\title{
Spatial Frequency Multiplier with Active Linearly Tapered Slot Antenna Array
}

Rainee N. Simons

Sverdrup Technology, Inc.

Lewis Research Center

Brook Park, Ohio

and

Richard Q. Lee

National Aeronautics and Space Administration

Lewis Research Center

Cleveland, Ohio

Prepared for the

1994 IEEE MTT-S International Microwave Symposium

sponsored by the Institute of Electrical and Electronics Engineers

San Diego, California, May 23-28, 1994

\section{N/SN}




\title{
SPATIAL FREQUENCY MULTIPLIER WITH ACTIVE LINEARLY TAPERED SLOT ANTENNA ARRAY
}

\author{
Rainee N. Simons \\ Sverdrup Technology, Inc. \\ Lewis Research Center Group \\ Brook Park, Ohio 44142 \\ and \\ Richard Q. Lee \\ National Aeronautics and Space Administration \\ Lewis Research Center \\ Cleveland, Ohio 44135
}

\begin{abstract}
A frequency multiplier with active linearly tapered slot antennas (LTSAs) has been demonstrated at the second harmonic frequency. In each antenna element, a GaAs monolithic microwave integrated circuit (MMIC) distributed amplifier is integrated with two LTSAs. The multiplier has a very wide bandwidth and large dynamic range. The fundamental-to-second harmonic conversion efficiency is 8.1 percent. The spatially combined second harmonic signal is $50 \mathrm{~dB}$ above the noise level. The design is suitable for constructing a large array using monolithic integration techniques.
\end{abstract}

\section{INTRODUCTION}

The power output of solid state devices decreases as the frequency of operation increases. Hence to obtain high power at millimeter wave frequencies, the power outputs from several devices, such as, IMPATT diodes, Gunn diodes, MESFETs or HEMTs, have to be combined using either conventional power combiners or quasi-optical power combiners (1). The quasi-optical power combining techniques that have been reported include spatial amplifiers, such as grid amplifiers using MESFETs (2), spatial frequency multipliers using varactor diodes (3), and harmonic combiners using FETs (4). Quasi-optical power combiners have higher combining efficiencies over conventional power combiners because of lower conductor losses and larger dimensional tolerances with the absence of resonant waveguide cavities. In addition, integrating both antennas and devices on a single semiconductor wafer simplifies the array construction.
This paper presents for the first time frequency multiplication and space power combining with an GaAs monolithic microwave integrated circuit (MMIC) distributed amplifier and an array antenna. In this approach an array of LTSAs (5) and GaAs MMIC distributed amplifiers (6) receives signal at a fundamental frequency, and after multiplication and amplification, radiates the second harmonic signal into free space. The advantages of using a distributed amplifier are a very large gain-bandwidth product and good input and output impedance match at both the fundamental frequency and the harmonic frequencies, and the advantages of using a LTSA are wide bandwidth, high gain and simple construction. In addition, unlike spatial oscillator array, the spatial multiplier array does not require injection locking for coherence and stability. However, it does require a high power source at the fundamental frequency for good conversion efficiency.

\section{SPATIAL ACTIVE MULTIPLIER FABRICATION AND CHARACTERISTICS}

The experimental three-element active array module is shown in Fig. 1. The array elements are constructed by integrating a GaAs MMIC distributed amplifier between two nonplanar LTSAs.

\section{GaAs MMIC Distributed Amplifier}

The GaAs MMIC distributed amplifier was developed by Texas Instruments for NASA Lewis Research Center (6). A photograph of the amplifier chip is shown in Fig. 2. The MMIC consists of six $300 \mu \mathrm{m}$ wide by $0.5 \mu \mathrm{m}$ long MESFETs and is $1.25 \mathrm{~mm} \times 2.63 \mathrm{~mm} \times 0.1 \mathrm{~mm}$. The bias network is 
incorporated on the chip. The amplifier typically has a linear gain of $5 \pm 1 \mathrm{~dB}$ over the frequency range of 2 to $22 \mathrm{GHz}$ with a power output of $0.5 \mathrm{~W}$ under large signal operation (Drain voltage $\mathrm{V}_{\mathrm{d}}=5.0 \mathrm{~V}$, Drain Current $\mathrm{I}_{\mathrm{d}}=570 \mathrm{~mA}$, and Gate voltage $\mathrm{V}_{\mathrm{g}}=0 \mathrm{~V}$ ). The power added efficiency at $0.5 \mathrm{~W}$ is 14 percent (6).

\section{Linearly Tapered Slot Antenna}

The feed system of the nonplanar LTSA consists of a conventional microstrip with the ground plane tapered to form a balanced microstrip. The strip conductors of the balanced microstrip are gradually flared with respect to the antenna axis to form the nonplanar LTSA (5). A photograph of the nonplanar LTSA is shown in Fig. 3. The antenna fabricated on a $0.508 \mathrm{~mm}$ RT-5880 Duroid substrate $\left(\varepsilon_{\mathrm{r}}=2.2\right)$ has a measured gain of $11 \mathrm{~dB}$ at $20 \mathrm{GHz}$ and return loss of better than $10 \mathrm{~dB}$ over the frequency range of 10 to $30 \mathrm{GHz}$.

\section{EXPERIMENTAL RESULTS AND DISCUSSIONS}

\section{Experimental Set-up}

A simple phased locked measurement setup has been developed to measure the second harmonic generated by the spatial multiplier. In the test setup which is shown in Fig. 1, the LTSAs at the input terminals are space-fed from a $\mathrm{X}$-Band waveguide horn antenna while those at the output terminals radiate into free space. The free space radiation is picked up by a K-Band waveguide horn antenna which is placed at a far field distance from the array. To establishes good isolation between the transmitting and receiving horn antennas, the two horn antennas are orthogonally polarized but the LTSAs are oriented to have the same polarization as their respective horn antennas. In addition, the waveguide feed dimensions of the receiving horn antenna are such that the transmitting frequency is far below cutoff. The signal received by the second horn antenna is fed to a balanced mixer which is followed by a narrow band IF amplifier. The local oscillator (LO) of the mixer is phased locked to the transmitting oscillator resulting in good signal-to-noise ratio and also elimination of spurious responses.

\section{Second Harmonic Generation}

The amplifiers were characterized before being inserted into the array. The conversion efficiency, $\eta$, of the fundamental frequency $\left(\mathrm{f}_{0}\right)$-to-second harmonic frequency $\left(2 \mathrm{f}_{0}\right)$ was determined from the measurements of the power output, $\mathrm{P}_{\text {out }}$, at $2 \mathrm{f}_{0}$ and the power input to the amplifier, $\mathrm{P}_{\text {in }}$, at $\mathrm{f}_{0}$. Experimentally it was observed that when the amplifier was biased in the nonlinear region $\left(\mathrm{V}_{\mathrm{d}} \approx 2.15 \mathrm{~V}, \mathrm{~V}_{\mathrm{g}} \approx 0 \mathrm{~V}\right)$, the $\mathrm{P}_{\text {out }}$ at $2 \mathrm{f}_{0}$ was a maximum. This is because at $\mathrm{V}_{\mathrm{g}} \approx 0 \mathrm{~V}$, the input signal drives the gate of the MESFET into forward conduction and hence the gate capacitance and the transconductance varies nonlinearly with the gate voltage. These nonlinear elements generate the second harmonic signal. The drain bias in each of the three MMICs was adjusted to produce a coherent output. Figure 4 shows the measured $\mathrm{P}_{\text {out }}$ as a function of $\mathrm{f}_{0}$ at a fixed $\mathrm{P}_{\text {in }}$ of $0 \mathrm{dBm}$. The relatively constant $P_{\text {out }}$ at $2 \mathrm{f}_{0}$ over the input frequency $\left(\mathrm{f}_{0}\right)$ range of 2 to $10 \mathrm{GHz}$ demonstrates the wide-band characteristics of the multiplier. $P_{\text {out }}$ is a maximum at about $f_{0}=9.3 \mathrm{GHz}$. Figure 5 shows the measured $\mathrm{P}_{\text {out }}$ as a function of $\mathrm{P}_{\text {in }}$ at a fixed frequency of $9.3 \mathrm{GHz}$. The results that $\mathrm{P}_{\text {out }}$ increases from about $-40 \mathrm{dBm}$ to $0 \mathrm{dBm}$ as $P_{\text {in }}$ increases from $-10 \mathrm{dBm}$ to $10 \mathrm{dBm}$ demonstrate the wide dynamic range of the multiplier. The maximum $\eta$ is about 8.1 percent which occurs when $P_{\text {in }}=10 \mathrm{dBm}$. The above measurements were carried out using a HP 8672A Synthesized Signal generator and a HP 8566B Spectrum Analyzer.

\section{Spatial Combining}

To demonstrate spatial combining, the LTSAs at the amplifier input were excited at $\mathrm{f}_{0}$ and the amplified $2 \mathrm{f}_{0}$ signal radiated from the array was received by the horn antenna. The measured E- and $\mathrm{H}$-Plane radiation pattern of the horn antenna at $2 \mathrm{f}_{0}$ with the amplifier turned $\mathrm{ON}$ is shown in Fig. 6. Also shown is the noise pattern when the amplifier is turned OFF. The $2 \mathrm{f}_{0}$ signal is $50 \mathrm{~dB}$ above the noise.

\section{CONCLUSIONS}

A wide bandwidth and large dynamic range spatial frequency multiplier with GaAs distributed amplifiers and LTSAs has been demonstrated. The maximum is about 8.1 percent. The amplitude of the $2 \mathrm{f}_{0}$ signal is $50 \mathrm{~dB}$ above the noise level.

\section{REFERENCES}

1. K. Chang, and C. Sun, "Millimeter-wave Power-combining techniques," IEEE Trans. Microwave Theory Tech., Vol. MTT-31, No. 2, pp. 91-107, Feb. 1983.

2. M. Kim, J.J. Rosenberg, R.P. Smith, R.M. Weikle, J.B. Hacker, M.P. DeLisio, and D.B. Rutledge, "A Grid Amplifier," IEEE Microwave Guided Wave Lett., Vol. 1, No. 11, pp. 322-324, Nov. 1991.

3. C.F. Jou, W.W. Lam, H.Z. Chen, K.S. Stolt, N.C. Luhmann, Jr., and D.B. Rutledge, "Millimeter-Wave Diode-Grid Frequency Doubler," IEEE Trans. Microwave Theory Tech., Vol. 36, No. 11, pp. 1507-1514, Nov. 1988. 
4. S. Kawasaki, and T. Itoh, " $40 \mathrm{GHz}$ Quasi-Optical Second Harmonic Spatial Power Combiner Using FETs and Slots," 1992 IEEE MTT-S Inter. Microwave Symp. Digest, pp. 1543-1546, June 1-5, 1992.

5. R.N. Simons, and R.Q. Lee, "Nonplanar Linearly Tapered Slot Antenna with Balanced Microstrip Feed," IEEE Antennas and Propagation Society Inter. Symp. Digest, Vol. IV, pp. 2109-2112, 1992.

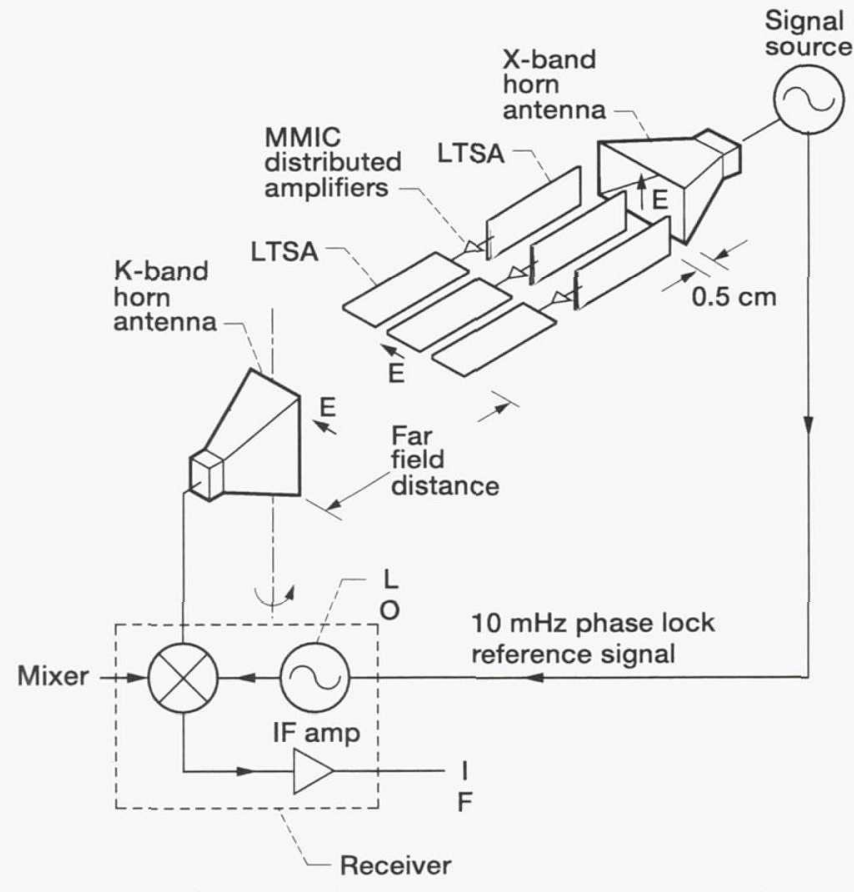

Figure 1.-Schematic illustrating an experimental setup for frequency multiplication and space power combining.
6 “20 GHz Monolithic Power Amplifier Module Development," Texas Instruments Final Technical Report, Contract No. NAS 3-23781.

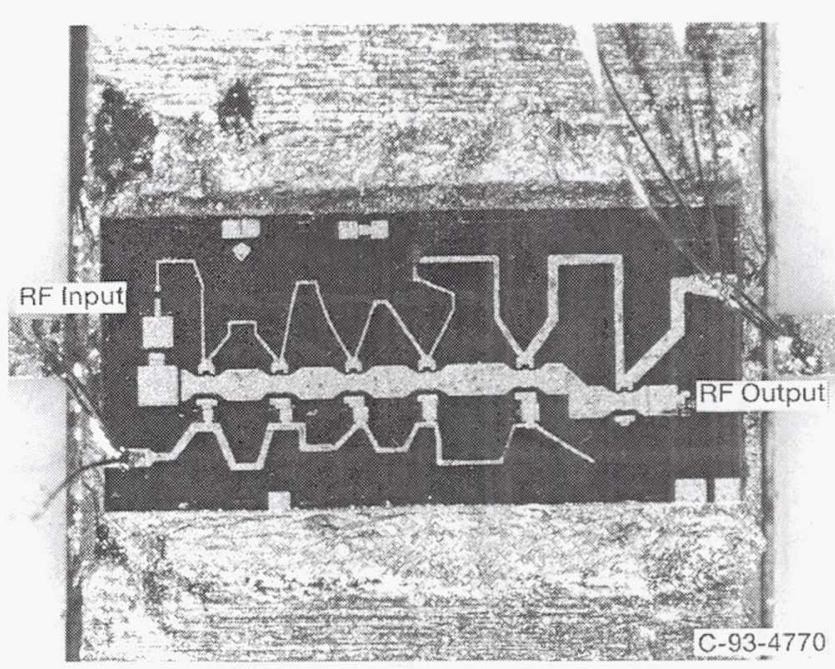

Figure 2.-GaAs MMIC distributed amplifier chip mounted on a heat sink and wire bonded to $50 \Omega$ microstrip lines on alumina at the input and output ports.

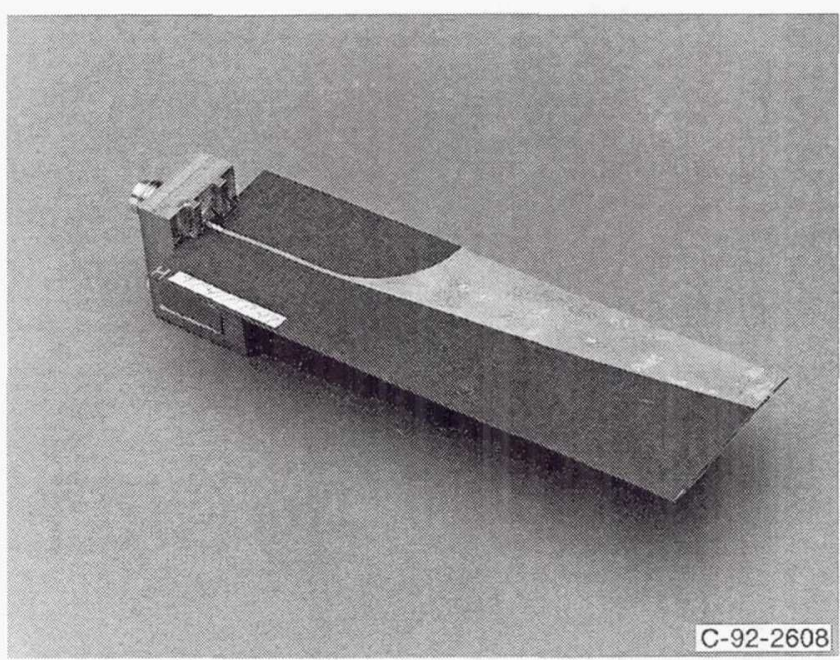

Figure 3.-Nonplanar linearly tapered slot antenna on duroid in a test fixture. 


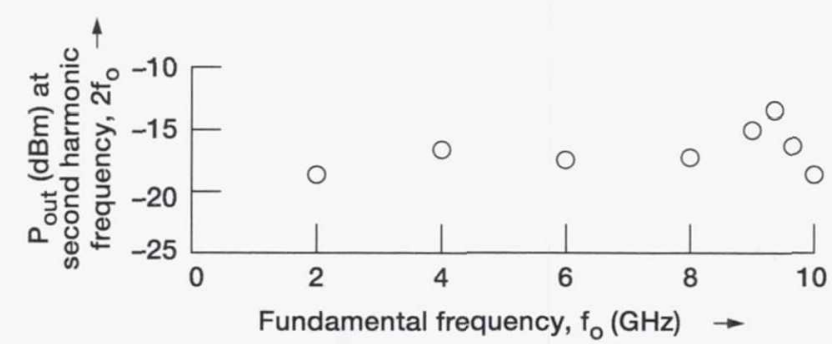

Figure 4.-Measured second harmonic output power as a function of fundamental frequency at a fixed input power of $0 \mathrm{dBm}$.

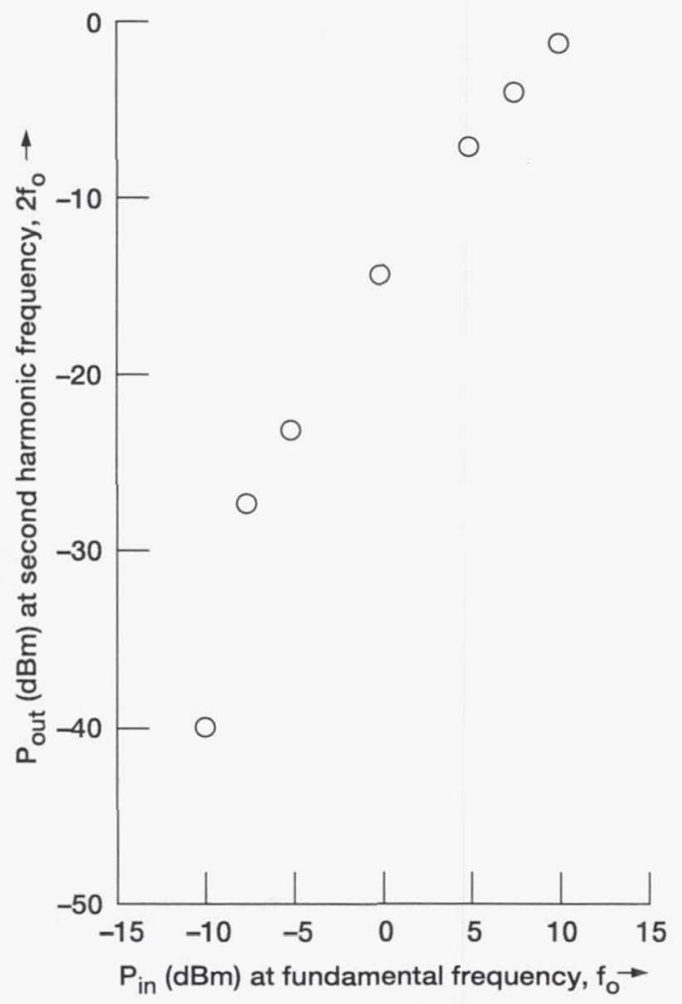

Figure 5.-Measured second harmonic output power as a function of input power at a fixed fundamental frequency of $9.3 \mathrm{GHz}$.
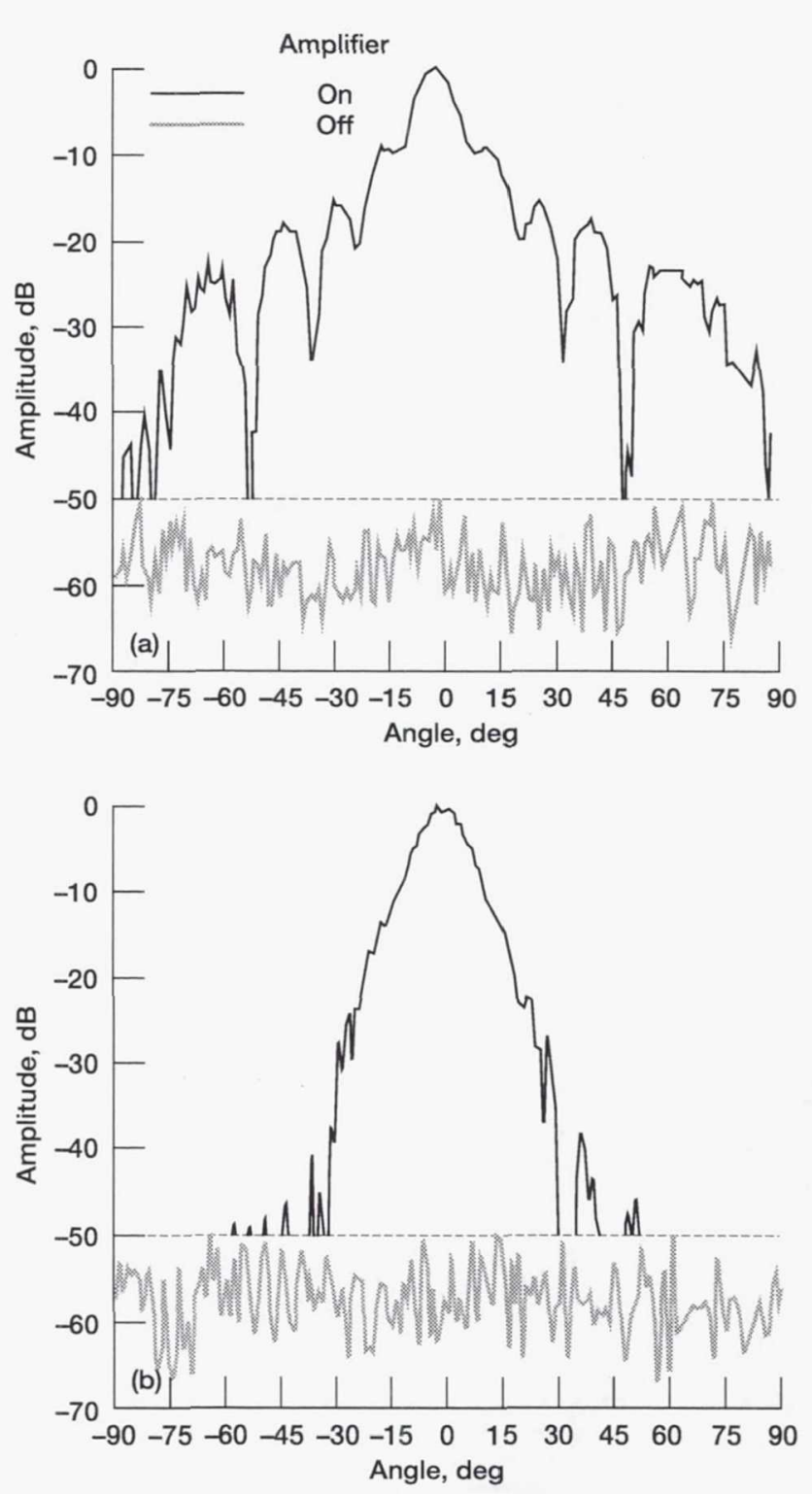

Figure 6.-Measured radiation pattern of the horn antenna showing space power combining at the second harmonic frequency of $17.9 \mathrm{GHz}$. (a) E-plane. (b) H-plane. 
Public reporting burden for this collection of information is estimated to average 1 hour per response, including the time for reviewing instructions, searching existing data sources, gathering and maintaining the data needed, and completing and reviewing the collection of information. Send comments regarding this burden estimate or any other aspect of this collection of information, including suggestions for reducing this burden, to Washington Headquarters Services, Directorate for Information Operations and Reports, 1215 Jefferson Davis Highway, Suite 1204, Arlington, VA 22202-4302, and to the Office of Management and Budget, Paperwork Reduction Project (0704-0188), Washington, DC 20503.

\section{TITLE AND SUBTITLE}

February 1994
Technical Memorandum

Spatial Frequency Multiplier with Active Linearly Tapered Slot Antenna Array

6. AUTHOR(S)

Rainee N. Simons and Richard Q. Lee

7. PERFORMING ORGANIZATION NAME(S) AND ADDRESS(ES)

National Aeronautics and Space Administration

Lewis Research Center

5. FUNDING NUMBERS

Cleveland, Ohio 44135-3191

9. SPONSORING/MONITORING AGENCY NAME(S) AND ADDRESS(ES)

National Aeronautics and Space Administration

Washington, D.C. 20546-0001

WU-506-44-2C

8. PERFORMING ORGANIZATION REPORT NUMBER

E-8060

11. SUPPLEMENTARY NOTES

Prepared for the 1994 IEEE MTT-S International Microwave Symposium sponsored by the Institute of Electrical and Electronics Engineers, San Diego, California, May 23-28, 1994. Richard N. Simons, Sverdrup Technology, Inc., Lewis Research Center Group, Brook Park, Ohio 44142 (work funded by NASA Contract NAS3-25266), presently at NYMA, Inc. Engineering Services Division, 2001 Aerospace Parkway, Brook Park, Ohio 44142 and Richard Q. Lee, NASA Lewis Research Center. Responsible person, Richard Q. Lee, organization code 5640, (216) 433-3489.

12a. DISTRIBUTION/AVAILABILITY STATEMENT

12b. DISTRIBUTION CODE

Unclassified - Unlimited

Subject Category 33

13. ABSTRACT (Maximum 200 words)

A frequency multiplier with active linearly tapered slot antennas (LTSAs) has been demonstrated at the second harmonic frequency. In each antenna element, a GaAs monolithic microwave integrated circuit (MMIC) distributed amplifier is integrated with two LTSAs. The multiplier has a very wide bandwidth and large dynamic range. The fundamental-to-second harmonic conversion efficiency is 8.1 percent. The spatially combined second harmonic signal is $50 \mathrm{~dB}$ above the noise level. The design is suitable for constructing a large array using monolithic integration techniques.

14. SUBJECT TERMS

Spatial frequency multiplier; Linearly tapered slot antenna; Array antenna

17. SECURITY CLASSIFICATION OF REPORT

Unclassified
18. SECURITY CLASSIFICATION OF THIS PAGE Unclassified
19. SECURITY CLASSIFICATION OF ABSTRACT Unclassified 